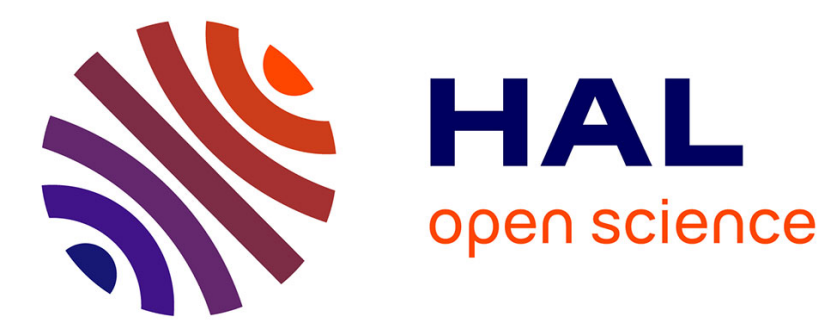

\title{
Tex55 encodes a conserved putative A-kinase anchoring protein dispensable for male fertility in the mouse
}

\author{
Soazik Jamin, Fabrice G. Petit, Leïla Demini, Michael Primig
}

\section{To cite this version:}

Soazik Jamin, Fabrice G. Petit, Leilla Demini, Michael Primig. Tex55 encodes a conserved putative A-kinase anchoring protein dispensable for male fertility in the mouse. Biology of Reproduction, 2021, 104 (4), pp.731-733. 10.1093/biolre/ioab007 . hal-03134538

\section{HAL Id: hal-03134538 \\ https://hal.science/hal-03134538}

Submitted on 25 Feb 2021

HAL is a multi-disciplinary open access archive for the deposit and dissemination of scientific research documents, whether they are published or not. The documents may come from teaching and research institutions in France or abroad, or from public or private research centers.
L'archive ouverte pluridisciplinaire HAL, est destinée au dépôt et à la diffusion de documents scientifiques de niveau recherche, publiés ou non, émanant des établissements d'enseignement et de recherche français ou étrangers, des laboratoires publics ou privés. 


\section{Tex55 encodes a conserved putative A-kinase anchoring protein}

\section{2 dispensable for male fertility in the mouse}

3

4 Soazik P. Jamin, Fabrice G. Petit, Leïla Demini, Michael Primig

5 Univ Rennes, Inserm, EHESP, IRSET (Institut de recherche en santé, environnement et 6 travail) - UMR_S 1085, F-35000 Rennes, France

8 Grant support: Infrafrontier, Institut Clinique de la Souris (ICS)

10 Corresponding authors:

11 soazik.jamin@inserm.fr, michael.primig@inserm.fr: IRSET ; 9, ave du Prof. Léon Bernard, 1235000 Rennes, France

14 Running title: Tex55 is not essential for male sexual reproduction

16 Summary sentence: The conserved putative A-kinase anchoring protein TEX55 is not

17 essential for spermatogenesis and fertility in the mouse.

19 Keywords: spermatogenesis, spermiogenesis, male fertility, Tex55, TSCPA, 4930435E12Rik,

20 C3orf30, AKAP 
24 Hundreds of genes are involved in human male sexual reproduction [1]. We previously

25 identified conserved genes for which expression patterns indicated a role in male fertility [2].

26 This group included Tex55 (TSCPA, C3orf30 in humans), which was proposed to possess an

27 A-kinase anchoring protein (AKAP) activity [3]. This marks Tex55 out as potentially

28 important, because several members of this protein family are required for normal spermatogenesis $[4,5]$. We first confirmed that Tex55 mRNA is detectable in adult but not fetal testis (E14.5) and that the transcript is absent in fetal (E14.5) ovary samples and nearly undetectable in adult ovary; Rpl13a was used as a control (Figure 1A). Next, we generated a gene deletion model using CRISPR/Cas9 in collaboration with the Institut Clinique de la Souris (www.ics-mci.fr/en/; Phenomin project; see Supplemental Methods). We obtained heterozygous mice harboring a mutant Tex55 allele lacking the first coding exon (Figure 1B). To generate the Tex55 knockout mice $\left(T e x 55^{-/}\right)$we intercrossed Tex $55^{+/-}$males and females. Tex $55^{+/+}$mice obtained via these crosses were used as controls. We validated the gene deletion phenotype using an RT-PCR assay and observed Tex55 mRNA expression in three control testes. As expected, no mRNA was detected in three homozygous mutant testes; Rpl13a was used as a control for the presence of mRNA (Figure 1C). Immunohistochemical analysis of mouse TEX55 using a newly raised antibody against the mouse protein, revealed

41 strong signals located at elongated spermatids and residual bodies in wild type testis, while no signal was detected in testis from homozygous mutant mice (Figure 1D). We subsequently crossed three to four months old males with mature fertile females over a period of eight months and scored the litter frequency and size. We found no significant difference for both parameters between control and knockout males (Supplementary materials). This result suggests that Tex55 is dispensable for male fertility in the mouse. We further analysed testes from wild-type, heterozygous and homozygous mutant mice and observed no differences in 
testicular weight and morphology (Figure 1E, F). Likewise, histological sections of adult testes revealed no alterations in tubular structure, somatic or germ cell numbers and sperm morphology (Figure 1G). We also detected no differences in the expression of the Leydig cell marker protein StAR in the presence or absence of TEX55 (Figure 1G) indicating that, as expected, the interstitial tissue is not affected either. Given that we detect neither mRNA nor protein in homozygous mutant samples, we conclude that the gene deletion approach was successful. It is, in any case, conceivable that the protein plays subtle roles in spermiogenesis or sperm/egg interactions that our assays were unable to detect. Another explanation is genetic redundancy. Since Efcab10 is now considered to be a Tex55 paralog in mouse and human, it could provide an explanation for our result. However, three pieces of evidence argue against Efcab10 being functionally equivalent to Tex55. First, single-cell RNASequencing (scRNA-Seq) data show that while Efcablo is also expressed in spermatids, it peaks earlier in germline development than Tex55 (Supplementary Figure S1). Second, the

61 level of Tex55/Efcab10 sequence conservation is extremely low (10.61\% target identity;

$623.67 \%$ query identity; see www.ensembl.org (Mouse GRCm38.p6). Third, EFCAB10 lacks

63 the critical domain for AKAPs, which means that the protein likely cannot compensate for 64 TEX55's postulated major role (www.uniprot.org). Alternatively, genes such as Cabyr, Ropn1l and Spa17, which show peak expression in round and elongated spermatids and possess protein kinase regulatory subunit dimerization-anchoring domains, might be

67 functionally redundant with Tex55 (Figure S1; see also www.proteinatlas.org). Moreover, scRNA-Sequencing data reveal that all three genes are expressed in late stage round spermatids, whereby Spal7 even peaks at that stage (Figure S1). The known roles of these genes are also in keeping with the idea that they might compensate for Tex55, since Cabyr is involved in sperm capacitation [6], Ropnll is important for sperm motility and integrity [7] and Spal7 was proposed to be involved in A-kinase anchoring [8]. We note that mutants 
73 lacking Ropn $1 \mathrm{l}$ are fertile, mice are available for Spal7 and engineered embryonic stem cells

74 were generated for Cabyr (www.mousephenotype.org), which marks them out as potentially

75 interesting candidates for double gene deletion experiments. Further mouse work involving

76 pair-wise crosses of Tex55 mutants with mutants bearing null alleles of paralogous or

77 functionally analogous genes may reveal their redundant roles in male fertility. 
81 Figure 1. Tex55 expression and deletion. (A) RT-PCR assay with testes and ovaries from E14.5 embryos and adults. Molecular weight markers (MW). Rpl13a was used as a loading control. (B) A schematic summarizes the wild-type (Tex55) and mutant (Tex55 DExI $)$ alleles. A black line is DNA, black rectangles are coding exons. Exon numbers are shown. Single guide RNA (sgRNA) positions are marked by red lines. Blue and green arrows symbolize PCR primers used for genotyping. Dotted lines mark the deleted sequence. (C) RT-PCR assay; lane 1 molecular weight markers (MW), lanes 2-4 wild type $(+/+)$ and lanes 5-7 homozygous mutant testes. Bands are annotated with gene names. (D) Images of an immunohistochemical assay were processed using NDP.view 2 software. Wild-type $(+/+)$ is compared to mutant (-/). A black bar is $100 \mu \mathrm{m}$. (E) Adult testes from wild-type $(+/+$, heterozygous $(+/-)$ and

91 homozygous (-/-) mice are shown. (F) Testis/body weight ratio of wild type and Tex55/mice. (G) Images of histological sections (HE) from wild-type (+/+) and homozygous (-/-) mutants are given. Images of an IHC assay for a Leydig cell marker (StAR) in wild-type and homozygous mutants are shown. Black bars indicate $50 \mu \mathrm{m}$. analogous genes. scRNA-Seq expression data for five genes in testicular cell types are shown. A color coded schematic outlines the scatter plot of data for peritubular cells (PT), Sertoli cells (SE), spermatogonia (SG), spermatocytes (SC) and round spermatids at different steps $(\mathrm{rST})$. 
104 1. Oud MS, Volozonoka L, Smits RM, Vissers L, Ramos L, Veltman JA. A systematic 105 review and standardized clinical validity assessment of male infertility genes. Hum Reprod 2019; 34:932-941.

2. Petit FG, Kervarrec C, Jamin SP, Smagulova F, Hao C, Becker E, Jegou B, Chalmel F, Primig M. Combining RNA and Protein Profiling Data with Network Interactions Identifies Genes associated with Spermatogenesis in Mouse and Human. Biol Reprod 2015.

3. Yu Z, Wu B, Tang A, Chen J, Guo X, Qin J, Gui Y, Cai Z. Expression profile of a novel germ cell-specific gene, TSCPA, in mice and human. J Huazhong Univ Sci Technolog Med Sci 2009; 29:535-539.

4. Miki K, Willis WD, Brown PR, Goulding EH, Fulcher KD, Eddy EM. Targeted disruption of the Akap4 gene causes defects in sperm flagellum and motility. Dev Biol 2002; 248:331-342.

5. Schimenti KJ, Feuer SK, Griffin LB, Graham NR, Bovet CA, Hartford S, Pendola J, Lessard C, Schimenti JC, Ward JO. AKAP9 is essential for spermatogenesis and sertoli cell maturation in mice. Genetics 2013; 194:447-457.

6. Naaby-Hansen S, Mandal A, Wolkowicz MJ, Sen B, Westbrook VA, Shetty J, Coonrod SA, Klotz KL, Kim YH, Bush LA, Flickinger CJ, Herr JC. CABYR, a novel calcium-binding tyrosine phosphorylation-regulated fibrous sheath protein involved in capacitation. Dev Biol 2002; 242:236-254.

7. Fiedler SE, Dudiki T, Vijayaraghavan S, Carr DW. Loss of R2D2 proteins ROPN1 and ROPN1L causes defects in murine sperm motility, phosphorylation, and fibrous sheath integrity. Biol Reprod 2013; 88:41.

8. Frayne J, Hall L. A re-evaluation of sperm protein 17 (Sp17) indicates a regulatory role in an A-kinase anchoring protein complex, rather than a unique role in spermzona pellucida binding. Reproduction 2002; 124:767-774. 

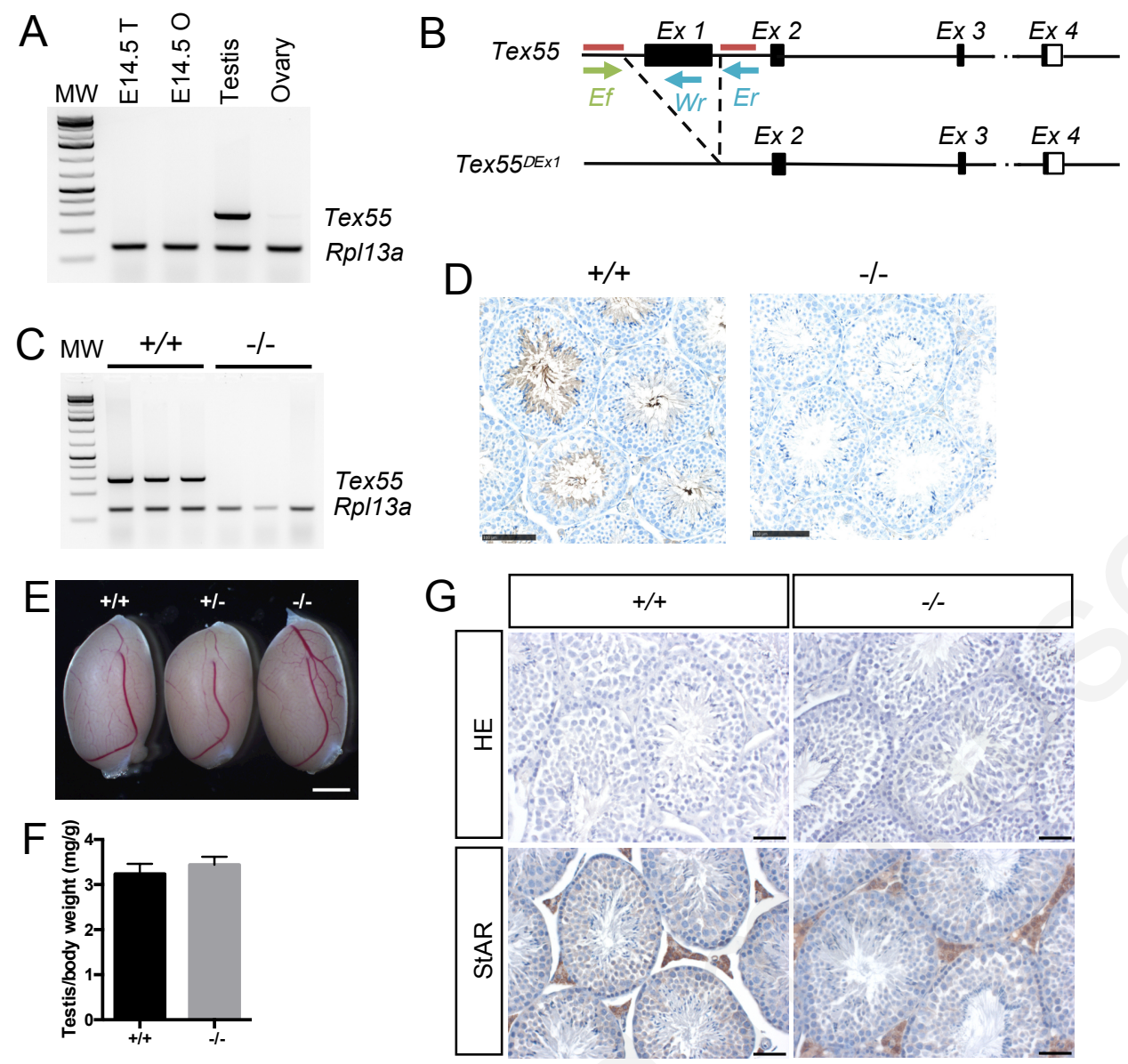

Figure 1 

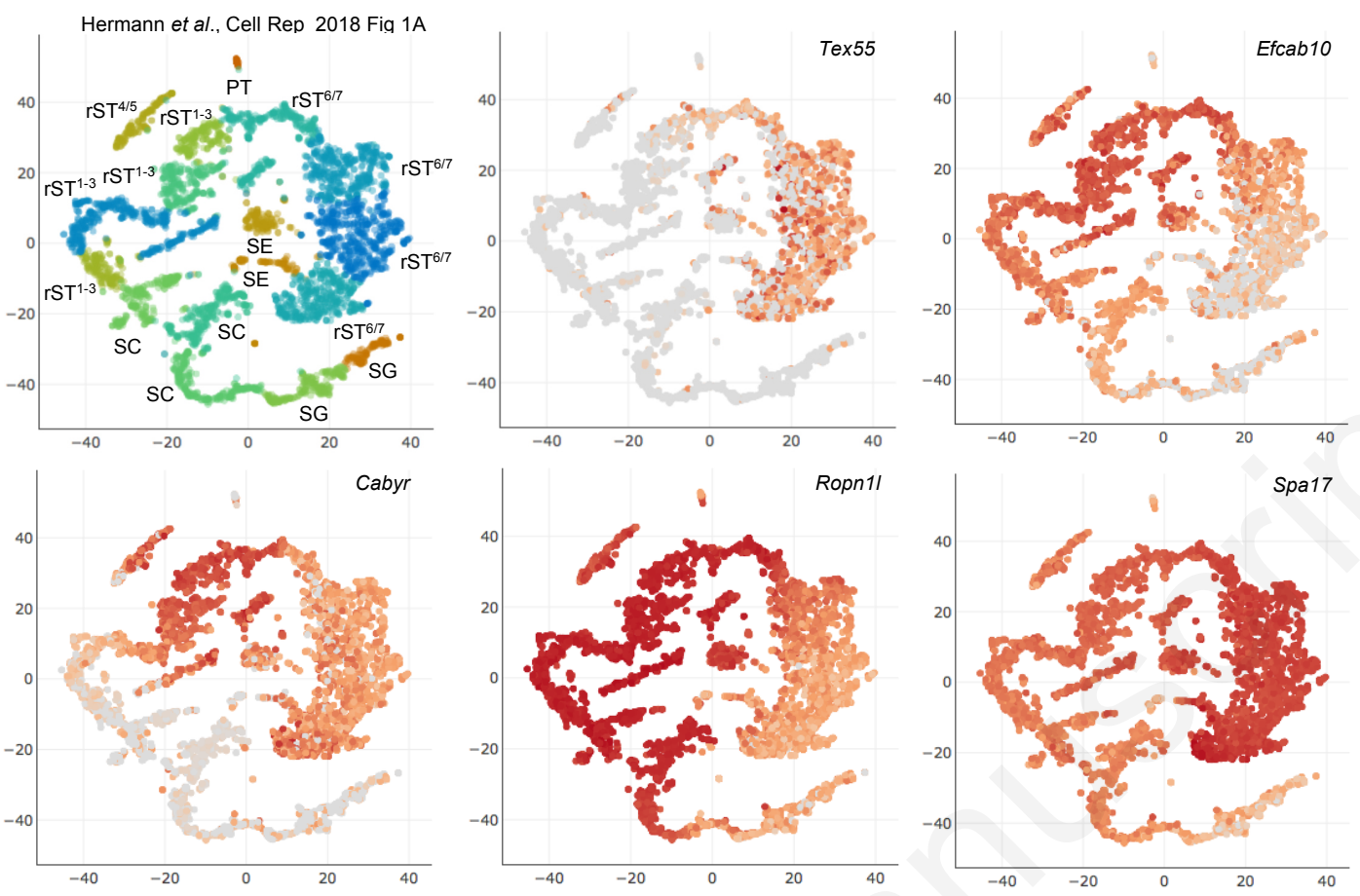

Supplemental Figure S1. scRNA-Seq expression data. A color-coded scatter plot in the top left corner shows the distribution of spermatogonia (SG), spermatocytes (SC), round spermatids at different stages (rST), Sertoli cells (SE) and peritubular cells (PT). Expression data for five genes are shown as indicated. Cells that express target genes are marked in shades of red. 


\section{Supplementary Methods}

\section{Ethics Statement}

Studies involving animals, including housing and care, method of euthanasia and experimental protocols were conducted in accordance with French legislation for Laboratory Animal Care, issued from the transposition of the European Directive 2010/63/UE. This Directive stipulates in article 1, alinea 2 that euthanizing laboratory animals for the sole purpose of investigating their tissues does not require prior authorization by an ethics committee. The animal facility was licensed by the French Ministry of Agriculture (C35-238-19). Animals were sacrificed using $\mathrm{CO} 2$, according to a method in annex IV of the directive. All experiments were supervised by Soazik P. Jamin who is licensed for animal experimentation by the French Ministry of Agriculture (92-299).

\section{Tex55 mouse gene expression}

Single-cell RNA-Sequencing (scRNA-Seq) data from mouse testicular cells were visualized using the ReproGenomics Viewer (http://rgv.genouest.org, [1]), [2].

\section{RT-PCR assays}

Adult and E14.5 ovaries and testes were dissected out from C57BL6 mice. The genomic DNA from the yolk sac was used to confirm the sex by PCR (see below). Total RNA was extracted using RNeasy Plus Mini kit (Qiagen, Courtaboeuf, France) for adult tissues or Arcturus Pico pure (ThermoFisher Scientific, Illkirch, France) for fetal gonads following the manufacturer's guidelines. Complementary DNAs (cDNAs) were synthesized with iScript RT Supermix (Biorad, Marnes-La-Coquette France) according to the manufacturer's instructions. Polymerase chain reaction (PCR) was set up with the four primers (Tex55 and Rpl13a) and the Taq DNA polymerase (Qiagen). The amplification conditions were 5 minutes at $95^{\circ} \mathrm{C}$, followed by 30 cycles of $94^{\circ} \mathrm{C}$ for 1 minute, $58^{\circ} \mathrm{C}$ for 1 minute, and $72^{\circ} \mathrm{C}$ for 1 minute, with a final 10 minute extension at $72^{\circ} \mathrm{C}$. The primers we used are listed in Table 1.

Table 1. Oligonucleotide sequences of PCR primers used for RT-PCR

\begin{tabular}{|l|l|}
\hline Name & DNA sequence \\
\hline m-Tex55-714-s & 5'-GCTCCCATCCAAAGTTTCAA-3' \\
\hline m-Tex55-1010-a & 5'-TCCACATAGCGAAGTGCAAC-3' \\
\hline m-Rp113a-L1 & 5'-CATGAGGTCGGGTGGAAGTA-3' \\
\hline m-Rp113a-R1 & 5'-GCCTGTTTCCGTAACCTCAA-3' \\
\hline
\end{tabular}




\section{Production of Tex55 heterozygous and homozygous mutant mice}

The Tex55 mutant mouse line was established at the Institut Clinique de la Souris PHENOMIN (http://www.phenomin.fr ) by a CRISPR/Cas9 approach [3]. The first coding exon of Tex55 (www.ensembl.org; ENSMUSE00000354274) encoding the N-terminal 297 amino acids was deleted using an approach based on two pairs of sgRNAs. sgRNA identification numbers refer to the MIT specificity score (http://crispor.tefor.net/crispor.py; Table 2). 161 fertilized oocytes from C57BL/6N mice were microinjected with a mixture of four sgRNAs (12 $\mathrm{ng} / \mu \mathrm{l}$ each) and spCas $9 \mathrm{mRNA}(25 \mathrm{~g} / \mu \mathrm{l})$. Among 16 pups (putative founders) analyzed by PCR six showed clear deletions of exon 1. Germline transmission of the mutated allele was achieved and a mouse line (Pus5945-13-DEL) was established, whereby all mice bore the same exon 1 deletion that was confirmed by junction sequencing. Finally, Tex $55^{+/-}$ mice were intercrossed to generate homozygous mutants. Tex $55^{+/+}$mice were used as controls.

Table 2. sgRNA sequences

\begin{tabular}{|l|l|}
\hline Name & Sequence \\
\hline 5'-sgRNA gR71 & GGCAGGTTCAGGCAGCGTGG \\
\hline 5'-sgRNA gR85 & AATCCAGATGGCCCACCTAT \\
\hline 3'- sgRNAs gR79 & GGTCAAAGGGATGTGCCGGG \\
\hline 3'- sgRNAs gR84 & GGTGGCATGTGTTAGTTATA \\
\hline
\end{tabular}

\section{Mouse genotyping}

Mouse genotyping was performed using DNA extracted from tail tips or yolk sac and a standard PCR assay. The primer sets 493Rik-Ef/493Rik-Er/493Rik-Wr were used to discriminate Tex55 $5^{+/+}$, Tex $55^{+/-}$and Tex $55^{-/-}$genotypes and the primer sets mZFY-1A/mZFY-1B were used to identify male and female fetuses. In post-natal mice, the genotyping was repeated twice at weaning and at the time of collection. Oligonucleotide primer sequences are shown in Table 3.

Table 3. Oligonucleotide sequences of PCR primers used for mouse genotyping

\begin{tabular}{|l|l|}
\hline Name & DNA sequence \\
\hline 493Rik-Ef & 5'-CTGTTCTCACTGGATCTTCCTGTTG-3' \\
\hline 493Rik-Er & 5'-GATCCTTCCTGAGTGGCCTGAG-3' \\
\hline 493Rik-Wr & 5'-GCCAATGGACGAGCAAGTATGA-3' \\
\hline mZFY-1A & 5'-CCTATTGCATGGACTGCAGCTTATG-3' \\
\hline mZFY-1B & 5'-GACTAGACATGTCTTAACATCTGTCC-3' \\
\hline
\end{tabular}




\section{Production of TEX55 polyclonal antibodies}

The rabbit polyclonal antibodies against mouse TEX55 were produced by ProteoGenix (Schiltigheim, France). Two rabbits were immunized with two peptides including the peptide TC-16 (TDTNDYRETGQRLQPC) that was conjugated to keyhole limpet hemocyanin (KLH) as a carrier molecule. The rabbits were boosted for 70 days and the antibodies were titrated by ELISA (Table 4) and affinity purified against the antigen according to standard protocols. The purified antibody was stored at $-80^{\circ} \mathrm{C}$ in $\mathrm{PBS}, 0.02 \%$ sodium azide, $\mathrm{pH}$ 7.4.

Table 4. ELISA titration for TEX55 antibodies

\begin{tabular}{|l|l|l|l|l|l|l|l|}
\hline Dilution & Blank & Negative & $\mathbf{1 : 1 0 0 0}$ & $\mathbf{1 : 4 0 0 0}$ & $\mathbf{1 : 1 6 0 0 0}$ & $\mathbf{1 : 3 2 0 0 0}$ & $\mathbf{1 : 6 4 0 0 0}$ \\
\hline Rabbit 1 & 0.057 & 0.055 & 1.925 & 1.496 & 1.025 & 0.685 & 0.364 \\
\hline Rabbit 2 & 0.061 & 0.052 & 1.968 & 1.514 & 1.174 & 0.752 & 0.418 \\
\hline
\end{tabular}

\section{Testicular morphology}

Testes from one year old males were dissected, weighed and observed under a stereo microscope Zeiss SteREO Discovery.V8 connected to an AxioCam IIc3 camera (Zeiss, France).

\section{Immunohistochemical analysis of TEX55 protein expression and localisation}

Immunohistochemistry experiments were performed on sections of eight week old mouse testes that were fixed in $4 \%$ paraformaldehyde and embedded in paraffin. Paraffin-embedded tissue was cut at $4 \mu \mathrm{m}$, mounted on positively charged slides and dried at $58^{\circ} \mathrm{C}$ for 60 minutes. TEX55 immunohistochemistry on mouse samples was performed by the Biosit H2P2 platform on the Discovery Automated IHC Stainer using the Ventana DABMap detection kit (Ventana Medical Systems, Tucson, USA). Following deparaffination with Ventana EZ Prep solution at $75{ }^{\circ} \mathrm{C}$ for 8 minutes, antigen retrieval was performed using Tris-based buffer solution CC1 (Ventana Medical Systems) at $95^{\circ} \mathrm{C}$ to $100^{\circ} \mathrm{C}$ for 36 minutes. Endogen peroxidase was blocked with Inhibitor-D 3\% H2O2 (Ventana Medical Systems) for 8 minutes at $37^{\circ} \mathrm{C}$. After rinsing with reaction buffer (Ventana Medical Systems), slides were incubated at $37^{\circ} \mathrm{C}$ for 60 minutes with TC-16 antibody (Proteogenix, 1:1000). After rinsing, signal enhancement was performed using the DABMap kit (Ventana Medical Systems) and the slides were incubated with the secondary antibody (biotinylated horse anti-rabbit) for 32 minutes. Slides were then counterstained for 16 minutes with hematoxylin and four minutes with bluing reagent before they were rinsed. After removal from the instrument, slides were manually dehydrated and a cover slip was placed on them. The slides were scanned and images were processed using NDP.view 2 software (gimage correction 1.5, brightness $110 \%$ and contrast 115\%; Hamamatsu, Japan).

StAR immunochemistry on mouse testes was performed as follows. After antigen retrieval in citrate buffer, the endogenous peroxidase was inactivated with $\mathrm{H}_{2} \mathrm{O}_{2}$. The slides were then blocked in 10\% BSA for one hour and the primary antibody (StAR, CST 8449, 1:200, Cell Signaling Technology) was incubated overnight at $4^{\circ} \mathrm{C}$. After rinsing with PBS, the biotinylated secondary antibody (goat anti-rabbit, Dako, 1:500) was incubated for two hours at room temperature. The Vectastain ABC complex (Eurobio, Les Ulis, France) was used to amplify the signal and the reaction was revealed with DAB Quanto (Fisher Scientific) for one 
minute. Histological sections were examined using an AxioImager microscope equipped with an AxioCam ICc1 camera and ZEN v.2.3 Blue edition (Zeiss, France).

\section{Assay for male fertility}

The control and knockout males were bred with wild-type females for a period of six months and the total number of pups was recorded.

Table 5. Mating assay of Tex55 mutant versus wild type mice.

\begin{tabular}{|c|c|c|c|c|c|c|}
\hline Genotype & $\begin{array}{l}\text { No of } \\
\text { males }\end{array}$ & $\begin{array}{l}\text { No of } \\
\text { pups }\end{array}$ & $\begin{array}{l}\text { No of } \\
\text { litters }\end{array}$ & $\begin{array}{l}\text { average } \\
\text { litter size }\end{array}$ & $\begin{array}{l}\text { standard } \\
\text { deviation }\end{array}$ & $\begin{array}{l}\text { mating } \\
\text { period }\end{array}$ \\
\hline$+/+$ & 2 & 96 & 14 & 7.14 & 3.55 & 32 weeks \\
\hline$-/-$ & 4 & 180 & 29 & 6.21 & 2.88 & 32 weeks \\
\hline
\end{tabular}

\section{Statistical analysis}

Prism 6 (GraphPad Software, San Diego, USA) was used to run the statistical tests and results showing a $p$-value $<0.05$ were considered to be statistically significant. A two-tailed student $t-$ test was performed and the graphs display the mean standard deviation.

\section{References}

1. Darde TA, Lecluze E, Lardenois A, Stevant I, Alary N, Tuttelmann F, Collin O, Nef S, Jegou B, Rolland AD, Chalmel F. The ReproGenomics Viewer: a multi-omics and cross-species resource compatible with single-cell studies for the reproductive science community. Bioinformatics 2019; 35:3133-3139.

2. Hermann BP, Cheng K, Singh A, Roa-De La Cruz L, Mutoji KN, Chen IC, Gildersleeve H, Lehle JD, Mayo M, Westernstroer B, Law NC, Oatley MJ, et al. The Mammalian Spermatogenesis Single-Cell Transcriptome, from Spermatogonial Stem Cells to Spermatids. Cell Rep 2018; 25:1650-1667 e1658.

3. Birling MC, Herault Y, Pavlovic G. Modeling human disease in rodents by CRISPR/Cas9 genome editing. Mamm Genome 2017; 28:291-301. 